«Nomeolvides». Promoción de las condiciones de bienestar de la salud mental en ancianos y ancianas Marta Pereyra, Sandra Cerino, Marcela Coronado, Mayra Aracena, María Cristina Cometto,

Patricia Fabiana Gómez, Susana Sanguinetti

Extensión en red (9), e011, septiembre 2018

ISSN 1852-9569 | https://doi.org/10.24215/18529569e011

http://perio.unlp.edu.ar/ojs/index.php/extensionenred

FPyCS | Universidad Nacional de La Plata

La Plata | Buenos Aires | Argentina

\title{
«Nomeolvides» \\ Promoción de las condiciones de bienestar de la salud mental en ancianos y ancianas
}

«Donotforgetme». Promotion of mental health welfare conditions for the elderly

\author{
Marta Pereyra' \\ martabpereyra@gmail.com | https://orcid.org/0000-0003-3714-9987 \\ Sandra Cerino' \\ sandra.cerino@hotmail.com \\ https://orcid.org/0000-0002-0453-5104 \\ Mayra Aracena ${ }^{1}$ \\ aracenamayra@gmail.com \\ https://orcid.org/0000-0001-7623-3925

\section{Patricia Fabiana Gómez ${ }^{1}$} \\ pgomez@fcm.unc.edu.ar \\ http://orcid.org/0000-0002-8731-6141 \\ Marcela Coronado' \\ marceale75@gmail.com \\ http://orcid.org/0000-0002-6155-597X

\section{María Cristina Cometto'} \\ ccometto@fcm.unc.edu.ar \\ http://orcid.org/0000-0003-4185-2608

\section{Susana Sanguinetti ${ }^{2}$} \\ susanabasilia@gmail.com \\ https://orcid.org/0000-0002-0346-1449
}

1 Universidad Nacional de Córdoba/ 2 Universidad Siglo XXI | Argentina

\section{Resumen}

El artículo da cuenta de las producciones realizadas en el proyecto interdisciplinario «Nomeolvides», que tuvo como objetivo la promoción de las condiciones de bienestar de la salud mental en una comunidad de adultos mayores en la ciudad de Córdoba (Córdoba, Argentina).

\section{Palabras clave}

promoción, salud mental, tercera edad, salud pública

\section{Abstract}

The article gives an account of the productions made in the interdisciplinary project «Forget-me-nots», which aimed at promoting mental health welfare conditions in a community of older adults in the city of Córdoba (Córdoba, Argentina).

\section{Keywords}

promotion, mental health, senior citizens, public health 


\section{Introducción}

El proyecto «NOMEOLVIDES» surge como una experiencia extensionista que articula el campo de la comunicación con el de la salud mental, con el objetivo desarrollar una producción de narraciones multimediales elaboradas de forma conjunta entre docentes, estudiantes y adultos mayores, por medio de un trabajo intercátedras, del que participaron tres unidades académicas y dos universidades: la cátedra Producción Radial, correspondiente a la Carrera de Publicidad de la Universidad Siglo 21; la cátedra Producción Radiofónica, correspondiente a la Facultad de Ciencias de la Comunicación, y la cátedra Enfermería en Salud Mental y Psiquiatría, correspondiente a la Escuela de Enfermería de la Facultad de Ciencias Médicas, ambas de la Universidad Nacional de Córdoba (UNC).

La Organización Mundial de la Salud (OMS), en su Plan de acción integral 2013-2020, expresa que la función esencial de la salud mental es la consecución de la salud de todas las personas. Enfocado en la consideración de la totalidad del ciclo de vida (lactancia, infancia, adolescencia, edad adulta y ancianidad), este Plan pretende alcanzar la equidad por medio de la cobertura sanitaria universal y hace hincapié en la importancia de la promoción y la prevención, priorizando los grupos vulnerables.

La respuesta de los organismos internacionales promueve el desarrollo de programas en pos de un envejecimiento activo y saludable, lo cual implica reflexionar sobre la complejidad de este abordaje y considerar las dimensiones de la participación y la inclusión social, los factores personales y las cuestiones relativas a los estilos de vida, el entorno de las personas mayores, los espacios de vida y los aspectos laborales, y las políticas de jubilación (Organización Panamericana de la Salud, 2009).

En la Argentina, la Ley Nacional sobre Protección de la Salud Mental (26.657), plantea como objetivo dejar atrás el viejo paradigma de la atención de la salud mental, centrado en la visión del hospital psiquiátrico, hacia la mirada comunitaria por medio de la promoción y la prevención, utilizando como herramienta el aporte de los medios de comunicación (Ministerio de Salud de Nación, 2016).

La promoción de la salud mental involucra acciones que apoyan a las personas a adoptar y a mantener estilos de vida saludables, un medioambiente seguro y coherente, y la participación activa dentro de la sociedad y la comunidad. Estos son factores protectores importantes del bienestar mental en la edad avanzada. También el apoyo de las familias, los coetáneos y los cuidadores juega un papel clave en la salud de las personas mayores. La promoción de la salud mental depende, en gran medida, de estrategias conducentes 
a que los ancianos y las ancianas cuenten con los recursos necesarios para satisfacer sus necesidades básicas, tales como protección y libertad, viviendas adecuadas mediante políticas apropiadas, programas sanitarios y sociales dirigidos específicamente a personas que viven solas, que habitan en el medio rural o que padecen sufrimiento psíquico o somático (Instituto de Mayores y Servicios Sociales, 2010). La prevención de la soledad y del aislamiento son medidas importantes para mejorar la salud psicofísica y el envejecimiento saludable.

Otro aspecto fundamental es propiciar un ambiente de respeto y de protección de los derechos civiles, políticos, socioeconómicos y culturales básicos, para aumentar las oportunidades de que mayor cantidad de personas tengan una participación más activa en la toma de decisiones sobre su salud y su calidad de vida (Nogueira Alcalá, 2009).

Es importante destacar que, desde este enfoque, las personas ancianas que se mantengan en actividad tendrán un proceso de envejecimiento más feliz y satisfactorio, debido a que continúan manteniendo relaciones y roles con la sociedad (Lanza Hernández, 2010).

En el marco de estos conceptos, el proyecto «NOMEOLVIDES» está inspirado en la necesidad de revalorizar el rol de los adultos y las adultas mayores en nuestra sociedad, mediante una experiencia de formación académica intergeneracional que permita una mirada transformadora hacia ese sujeto que cursa una etapa más dentro del ciclo vital, muchas veces desestimada por los profesionales, la comunidad y la sociedad (Fernández Alba, García Pérez \& Santisteban Fernández, 2012).

\section{La propuesta de intervención extensionista}

El proyecto forma parte de una serie de trabajos de articulación y de intercambio entre actores de campos y de disciplinas diversas que decidieron vincularse y asociar sus esfuerzos, sus experiencias y sus conocimientos para la promoción de la salud mental en una comunidad específica de adultos y adultas mayores: el Hogar Padre Lamónaca, un geriátrico público municipal de la ciudad de Córdoba (Córdoba, Argentina). La iniciativa contó con la participación de docentes y estudiantes de tres unidades académicas de dos universidades nacionales que interactuaron con profesionales y con un grupo de adultos y de adultas mayores de la institución para la realización narrativas multimediales luego publicadas en una plataforma en línea (blog). 
La problemática social real de la que se partió - los adultos y las adultas mayores vulnerables albergados/as en una institución pública- actuó como motivadora para la gestión del aprendizaje por parte de los y las estudiantes. En paralelo, el proyecto pretendió sensibilizar a la comunidad en general sobre la temática de la tercera edad. Esta búsqueda encontró respaldo en el trabajo interdisciplinario de dos campos: el de la comunicación y el de la salud. El primero, abordado de las cátedras Producción Radiofónica (Universidad Nacional de Córdoba) y Publicidad (Universidad Siglo XXI); el segundo, desde la cátedra Enfermería en Salud Mental y Psiquiatría (Universidad Nacional de Córdoba); cada una realizó aportes desde sus saberes y sus habilidades.

El proyecto interdisciplinario de cruce generacional se designó con el nombre de fantasía «NOMEOLVIDES», inspirado en una flor diminuta de color azul, símbolo de la resistencia y del amor eterno.

Los objetivos fueron:

- Reconocer la problemática social de los adultos y las adultas mayores vulnerables.

- Promover la construcción de vínculos intergeneracionales en el encuentro entre los y las estudiantes universitarios y los adultos y las adultas mayores.

- Ofrecer a los y las estudiantes estrategias pedagógicas innovadoras a través de la extensión.

- Valorizar y sostener este espacio interdisciplinario para el abordaje de las temáticas sociales.

- Concebir, diseñar y realizar productos comunicacionales destinados a sensibilizar a la comunidad sobre el tema adultos y adultas mayores vulnerables.

Su desarrollo se organizó en cinco etapas acordadas entre los y las participantes:

Etapa 1 - Construcción del vínculo intergeneracional entre estudiantes y adultos y adultas mayores y formación de los grupos de trabajo. Se realizaron visitas con todos los y las estudiantes y los y las docentes para facilitar la vinculación con el personal de la institución y con los abuelos y las abuelas que quisieran participar. Se constituyeron equipos interdisciplinarios integrados por seis alumnos y alumnas de las tres cátedras y un docente facilitador. La elección de un tema sobre la «tercera edad» se realizó entre todos y todas, siempre orientado a la promoción de la salud mental. 
Etapa 2 - Selección de la temática que deseaban trabajar. Los alumnos y las alumnas realizaron una investigación bibliográfica y construyeron un marco de referencia sobre el Hogar Padre Lamónaca que incluyó aspectos históricos, geográficos, particularidades, accesibilidad y funcionamiento. También se relevó información acerca de la construcción de blogs (características, posibilidades que brinda, etc.). Estas indagaciones se efectuaron de manera grupal y fueron presentadas en un encuentro plenario con todos los y todas las integrantes del proyecto, del cual se desprendieron informes entregados mediante el sistema de aulas virtuales de cada facultad.

Etapa 3 - Recolección de materiales, audios, imágenes, textos y construcción del esquema preliminar del blog. Con la finalidad de construir textos narrativos sobre las vivencias y las perspectivas sobre las temáticas seleccionadas, se desarrolló una serie de encuentros personalizados entre los y las estudiantes y los adultos y las adultas mayores del Hogar Padre Lamónaca. Los encuentros fueron registrados en formato sonoro, audiovisual y de notas por cada grupo y su contenido estaba en relación con el factor protector de la salud mental abordado por el grupo.

Etapa 4 - Producción colectiva de un blog sobre la temática que incluye entrevistas, fotos e historias de vida. Junto con los tutores de la práctica — una vez completados todos los materiales necesarios para la producción - se desarrolló el producto final multimedial, que consistió en el diseño y el desarrollo de una entrada de blog por cada grupo, en la que se utilizaron sonidos, texto y fotografías. Puede accederse a las 33 narrativas multimediales en el sitio «Proyecto NOMEOLVIDES», https://proyectonomeolvides.wordpress.com

Etapa 5 - Socialización del proyecto mediante la exposición de las producciones en la institución geriátrica. Se presentó el blog en el Hogar, en un evento público del que participaron los alumnos y las alumnas, los y las docentes, los adultos y las adultas mayores, y las autoridades de las instituciones intervinientes en el proyecto.

Las narrativas producidas fueron: «Hablar de amor»; «Momentos»; «Las costumbres son hábitos que nos dan identidad»; «Amor de rosa»; «¡A nuestros queridos viejos!»; «Amistad y vínculo»; «Una vida feliz»; «¿Qué tal si vamos a jugar?»; «Los días de la vida»; «Viejas pociones»; «Recordar el volver a vivir»; «De tanto ser feliz»; «El saber, yo aprendo: aprendiendo juntos en el camino»; «La vida es un tango que hay que saber cantar»; «Autoestima, un factor necesario para una vejez plena»; «Los valores de mi hogar»; «La vida entre costuras»; «La raíces de nuestro presente»; «ißExclusión!! ¡iLlegaste al lugar indicado!! Aquí la solución a todos tus males»; «Cambio y resiliencia»; «De piropos y apuestas»; «Siete años después: historias para la eternidad»; «La libertad en Daniel»; «De todo un poco»; 
«Tiempos a solas»; «Comidas, sabores y recuerdos»; «Una luz en los jardines del tiempo»; «La vida son sueños»; «Los cuentos de la abuela Eva»; «Recuerdos de algodón»; «El jardín de los recuerdos»; «El valor de los abuelos»; $\mathrm{y}$ «Para sentir no hay edad».

\section{Evaluación de los éxitos, los aprendizajes conjuntos y las dificultades}

Este trabajo, realizado desde la formación académica de grado con carácter extensionista, ha enriquecido la mirada sobre la vejez como una etapa más de la vida y como un espacio de trabajo interdisciplinario posible. Las relaciones que se establecieron en este tipo de cruces impactaron en los objetivos actitudinales de las cátedras, al fortalecer la formación humanista de los y las estudiantes.

Otro aspecto positivo fue el desarrollo de un proceso de comunicación como práctica social, hecho cultural que vincula y que, al hacerlo, construye significados para quienes participan de la acción comunicativa. En estas prácticas se pusieron en juego cuestiones sociales, afectivas, gustos, modos de vivir, juicios y opiniones entre los y las participantes, se entablaron relaciones y se compartió, algunas veces de manera directa y otras por medio de algún canal de naturaleza técnica que permitió la interacción (Mata, 1985).

Uno de los mayores éxitos alcanzados fue el cruce generacional de los ancianos y las ancianas con los y las estudiantes universitarios/as. La afectividad puesta en juego desde los roles abuelo/a-nieto/a fue movilizante en ambos extremos generacionales, al producir evocaciones, expresiones de su interioridad, redescubrimientos de lazos afectivos y una reconciliación con sus historias personales. La realización del proyecto también permitió que los ancianos ejercieran sus derechos a la recreación, a expresarse, a participar, a reconocer sus necesidades y sus deseos, a recordar, a planificar y a verbalizar sus saberes y sus historias personales (Gumucio-Dagron, 2011).

En total, se produjeron 33 narrativas multimediales desde una pedagogía crítica y reflexiva, y atravesadas por una pluralidad de voces, lo que generó una experiencia práctica innovadora. En esta línea, la producción de las narraciones no solo tuvo potencialidad artística y comunicativa en sus lenguajes, sino que fue un recurso favorecedor para el desarrollo de condiciones de bienestar.

La concepción con la que se enfocó esta práctica extensionista reconoció el potencial creativo, la necesidad de aprender, de compartir, de disfrutar que tienen los adultos y las adultas mayores y su rol como productores y productoras. 
Como se desprende de los informes realizados por estudiantes de la Universidad Siglo XXI, el proyecto ha logrado cambios significativos en la vida de los actores principales: «[...] a veces me sentí incomoda, pero a pesar de eso valió la pena. Después de ver todo, los prejuicios lo único que generan son barreras que nos separan de eso que puede sacarnos una sonrisa» (Informe de alumnos, aula virtual, 2016).

Otra de las participantes afirmó:

[...] tuvimos una gran expectativa e intriga al tratarse de un proyecto tan distinto a lo que veníamos realizando y con personas [cuya] carrera variaba muchísimo de la nuestra, pero la experiencia superó mis expectativas. De este trabajo surgieron momentos lindos y emotivos, y otros en los que tuve que afrontar situaciones con el grupo, pero estoy contenta (Informe de alumnos, aula virtual, 2016).

Con respecto a la modalidad de trabajo propuesta, tanto el sistema de aprendizaje innovador que enfatizó la participación activa en la gestión autónoma de cada equipo de trabajo como el intercambio interdisciplinario promovieron el desarrollo de habilidades de consolidación de acuerdos básicos ideológicos, el aprendizaje de un trabajo colectivo con un marco referencial común, el planteo de una temática y el despliegue de acciones conjuntas para lograr el producto final.

En cuanto a las dificultades que se presentaron, es posible señalar: los problemas para lograr la articulación entre las diferentes disciplinas, para alcanzar acuerdos de trabajo, para tolerar al que piensa diferente, para argumentar posiciones y para ceder en pos de lograr un objetivo común.

\section{Conclusiones}

El propósito del proyecto interdisciplinario de cruce generacional «NOMEOLVIDES» fue la promoción de las condiciones de bienestar de la salud mental en los ancianos y las ancianas, objetivo que fue logrado y que superó las expectativas de los actores involucrados, ya que rompió el estereotipo que existe sobre la vejez como enfermedad. Estas ideas preexistentes fueron cuestionadas por los mismos actores que avanzaron hacia un concepto de vejez activa donde el sujeto se autodefine como un ser de emociones que transita de manera diferente la vida. 
El desafío pedagógico de una ideología reflexiva y crítica en el hacer desde la interdisciplinariedad, mediante una pluralidad de voces aunadas, confluyó en una nueva construcción colectiva. Vincular la universidad con el entorno permitió difundir conocimientos y tecnologías, que ofrecieron una respuesta factible en una comunidad de adultos y adultas mayores, a la vez que brindaron la oportunidad de aprendizajes vivenciales a futuros profesionales.

\section{Referencias}

Fernández Alba, N.; García Pérez, F. y Santisteban Fernández, A. (2012). Introducción: Educar para la participación ciudadana en la enseñanza de las ciencias sociales (pp. 13-16). Sevilla, España: Díada.

Gumucio-Dagron, A. (2011). Comunicación para el cambio social: clave del desarrollo participativo. Signo y Pensamiento, (58), 26-39. Recuperado de https://revistas.javeriana.edu.co/index.php/signoypensamiento/article/view $/ 2454$

Lanza Hernández, W. (2010). El envejecimiento global: intencionalidad y actitud interna. Un análisis existencial [Tesis de doctorado]. Recuperado de https://repositorio.uam.es/bitstream/handle/10486/4774/31450_lanza_her nandez_wilfredi.pdf?sequence= 1

Mata, M. C. (1985). Nociones para pensar la comunicación y la cultura masiva. Ciudad Autónoma de Buenos Aires, Argentina: La Crujía.

Ministerio de Salud Presidencia de la Nación (2016). Comunicación responsable. Recomendaciones para el tratamiento en los medios de comunicación de la salud mental. Recuperado de http://www.msal.gob.ar/images/stories/bes/graficos/0000000479cntrecomendaciones-tratamiento-temas-salud-mental-medios.pdf

Instituto de Mayores y Servicios Sociales (2010). La salud mental y el bienestar de las personas mayores. Hacerlo posible. Boletín sobre el envejecimiento, (46). Recuperado de http://www.imserso.es/InterPresent2/groups/imserso/documents/binario/ boletinopm46.pdf 
Nogueira Alcalá, H. (2009). Los derechos económicos, sociales y culturales como derechos fundamentales efectivos en el constitucionalismo democrático latinoamericano. Estudios constitucionales, 7(2), 143-205. Recuperado de http://www.estudiosconstitucionales.cl/index.php/econstitucionales/article/ view/226

Organización Mundial de la Salud (2013). Plan de acción sobre salud mental 2013-2020. Recuperado de http://apps.who.int/iris/bitstream/10665/97488/1/9789243506029_spa.pd f?ua $=1$

Organización Panamericana de la Salud (2009). Plan de acción sobre la salud de las personas mayores incluido el envejecimiento activo y sano. Estrategia Regional. Documento en preparación para el $144^{\circ}$ Comité Ejecutivo.

Recuperado de http://apps.who.int/gb/ebwha/pdf_files/WHA69/A69_ACONF8-sp.pdf 